\title{
Alain Cullière, Compléments bibliographiques sur les imprimeurs messins Jean d'Arras et Odinet Basset (1563-1564)
}

Filippo Fassina

\section{(2) OpenEdition}

Journals

\section{Edizione digitale}

URL: http://journals.openedition.org/studifrancesi/6246

DOI: $10.4000 /$ studifrancesi.6246

ISSN: 2421-5856

\section{Editore}

Rosenberg \& Sellier

\section{Edizione cartacea}

Data di pubblicazione: 1 novembre 2010

Paginazione: 542

ISSN: 0039-2944

\section{Notizia bibliografica digitale}

Filippo Fassina, «Alain Cullière, Compléments bibliographiques sur les imprimeurs messins Jean d'Arras et Odinet Basset (1563-1564)», Studi Francesi [Online], 162 (LIV | III) | 2010, online dal 30 novembre 2015, consultato il 13 janvier 2021. URL: http://journals.openedition.org/studifrancesi/6246 ; DOI: https:// doi.org/10.4000/studifrancesi.6246

Questo documento è stato generato automaticamente il 13 janvier 2021.

\section{cc) $($ ) $\ominus$}

Studi Francesi è distribuita con Licenza Creative Commons Attribuzione - Non commerciale - Non opere derivate 4.0 Internazionale. 


\section{Alain Cullière, Compléments bibliographiques sur les imprimeurs messins Jean d'Arras et Odinet Basset (1563-1564)}

Filippo Fassina

\section{NOTIZIA}

ALAIN CULLIÈRE, Compléments bibliographiques sur les imprimeurs messins Jean d'Arras et Odinet Basset (1563-1564), «Bibliothèque d'Humanisme et Renaissance», LXX, 3 (2008), pp. 609-612.

1 Il presente intervento va a completare uno studio apparso sulla medesima rivista («Bibliothèque d'Humanisme et Renaissance», LXVII (2005), pp. 673-700), riguardante gli editori riformati Jean d'Arras e Odinet Basset, attivi a Metz negli anni 1563-1564. In seguito a nuove acquisizioni e all'evoluzione degli strumenti di consultazione digitale, il catalogo è stato ampliato con l'aggiunta di testi prima sconosciuti che permettono una valutazione più ampia sulla produzione editoriale in questione. Non solo viene confermata l'alta qualità dei testi stampati a Metz, ma emerge anche una linea editoriale che va oltre alla semplice propaganda religiosa, per porsi all'interno di un più vasto quadro culturale e letterario. 